\title{
Party Identification, Issue Attitudes, and the Dynamics of Political Debate
}

\author{
Logan Dancey University of Minnesota \\ Paul Goren University of Minnesota
}

\begin{abstract}
This article investigates whether media coverage of elite debate surrounding an issue moderates the relationship between individual-level partisan identities and issue preferences. We posit that when the news media cover debate among partisan elites on a given issue, citizens update their party identities and issue attitudes. We test this proposition for a quartet of prominent issues debated during the first Clinton term: health care reform, welfare reform, gay rights, and affirmative action. Drawing on data from the Vanderbilt Television News Archives and the 1992-93-94-96 NES panel, we demonstrate that when partisan debate on an important issue receives extensive media coverage, partisanship systematically affects - and is affected by-issue attitudes. When the issue is not being contested, dynamic updating between party ties and issue attitudes ceases.
\end{abstract}

$\mathrm{P}$ olitical debate is not constant. Some issues rise quickly on the political agenda to be debated fiercely by partisan elites for a brief period, only to disappear without a trace shortly thereafter. On other issues, political debate continues for years. The dynamic nature of political debate produces peaks and valleys in news media coverage of issues, which in turn leads citizens to think about specific issues to varying degrees over time (Baumgartner and Jones 1993; Iyengar and Kinder 1987). When partisan elites debate an issue and the news media cover it, partisan predispositions are activated in the minds of citizens and subsequently constrain their policy preferences (Zaller 1992). Moreover, those who view an issue as personally important and know where the parties stand on the matter update their partisan identities to reflect their issue preferences (Carsey and Layman 2006).

Although public opinion scholars have studied relationships between partisanship and issue preferences for some time (Franklin and Jackson 1983; Green and Palmquist 1990), little is known about whether the dynamics of political debate influence these relationships. Does evolving political debate affect whether citizens connect their partisan identities and issue preferences, or do citizens update irrespective of media coverage of elite debate? The answer to this question has important implications for understanding mass-elite linkages. Insofar as citizens remain oblivious to political debate, their connections to the institutions of representative government become increasingly tenuous. But if citizens respond sensibly to changes in the information environment, those connections grow stronger.

This article examines whether changes in the volume of media coverage of political debate surrounding an issue moderate the relationship between individuallevel partisan identities and preferences on that issue. We argue that party identification and policy preferences dynamically constrain one another when partisan elites are visibly contesting the issue and the media cover this debate. Specifically, we posit that heightened partisan elite debate on a given issue is associated with increased media attention devoted to that issue. This increased media attention cues citizens that the issue divides the parties, prompting them to update their policy and party preferences accordingly. In the absence of media coverage of issue debate, individuals no longer receive cues that the issue is an important point of cleavage between the parties, and thus, they cease to update.

Logan Dancey is a Ph.D. candidate in Political Science, University of Minnesota, Minneapolis, MN 55455 (dance009@umn.edu). Paul Goren is Associate Professor of Political Science, University of Minnesota, Minneapolis, MN 55455 (pgoren@umn.edu).

We thank Marc Hetherington, Gary Jacobson, the three anonymous reviewers, and Marianne Stewart for their comments and suggestions on how to improve earlier versions of the manuscript. The authors' names are listed alphabetically. They contributed equally to the article, including any remaining errors.

American Journal of Political Science, Vol. 54, No. 3, July 2010, Pp. 686-699 
We test this model as follows. First, we identify four issues associated with varying levels of partisan elite debate-and subsequent news media coverage of that debate-during the first Clinton administration: health care reform, welfare reform, gay rights, and affirmative action. Second, we utilize TV news story counts from the Vanderbilt Television News Archives to estimate how much media coverage each issue received over the relevant time frames. Third, we apply structural equation modeling techniques to data from the 1992-93-94-96 NES panel to estimate dynamic relationships between party identification and preferences on these issues. We find that when partisan elite debate around an issue receives extensive media coverage, individuals' party identifications systematically affect — and are affected by — their attitudes on that issue. When coverage of elite debate on that issue wanes, the dynamic relationship between party and policy no longer exists. Put simply, when partisan elites debate political issues and this discourse is covered by the news media, citizens respond by rethinking the connections between their partisan loyalties and issue preferences.

\section{Conceptual and Theoretical Framework}

In the classic conceptualization, party identification can be defined as an enduring sense of psychological attachment to the Democratic or Republican Party (Campbell et al. 1960). Considerable research suggests that party identification functions as a perceptual screen coloring how partisans interpret, store, and retrieve political information (Berinsky 2007; Campbell et al. 1960; Evans and Andersen 2006; Goren 2002; Goren, Federico, and Kittilson 2009). For instance, Bartels (2002) demonstrates that partisanship biases what people believe is true, while Gaines et al. (2007) find that partisanship colors the interpretation of politically inconvenient facts. Green, Palmquist, and Schickler dispute the notion that party serves as a perceptual screen, arguing instead that, like religious identifiers, partisan identifiers "absorb the doctrinal positions that the group advocates" $(2002,4)$. By either mechanism, then, partisanship can be expected to shape political attitudes and beliefs.

In contrast to classical perspectives, which stress the causal priority of partisanship, revisionist models see party identification as responsive to short-term political forces. In this conceptualization, party identification functions partly as a "running tally" whereby citizens update their partisanship to reflect their stands on salient issues (Franklin and Jackson 1983), and their beliefs about how national and international conditions have changed under the incumbent administration (Fiorina 1981). This perspective is normatively appealing because it suggests that citizens are not simply impassive consumers of partisan spin, but rather, prove responsive to real-world events. However, Bartels (2002) and Green and Palmquist (1990) have shown that once the biasing effects of random measurement error in statistical models of partisan updating are accounted for, evidence supporting the revisionist model evaporates. This does not prove that the revisionist model is without merit, but instead suggests that the conditions facilitating partisan updating are harder to identify than initially anticipated.

Recent scholarship has advanced our understanding by specifying individual-level factors that enable issue-induced partisan change. Most notably, Carsey and Layman (2006) argue that issue preferences and party identification foster dynamic change in one another among individuals possessing various characteristics. Relying on structural equation modeling techniques that remove the biasing effects of random measurement error, Carsey and Layman demonstrate that when citizens know how the parties differ on an issue but do not consider the matter personally important, they modify their issue stance to conform to their party. However, when citizens are aware of party differences and view the issue as personally important, they simultaneously update their party ties and policy preferences. Consistent with the classic model, the effects of party on issues typically exceed those of the reverse causal chain, a point Carsey and Layman acknowledge: "we view our findings as further confirmation that party identification is a 'moving force in politics' that tends to be moved itself in only special circumstances" $(2006,474)$. Of course, the fact that party identification is updated under special circumstances lends credence to the revisionist model of party identification.

This modification of conventional wisdom on partisanship strikes us as quite sensible on theoretical grounds. Furthermore, it immediately raises another important question: if individual-level predispositions moderate the relationship between party and issues, might not situational-level factors produce comparable effects? Whereas Carsey and Layman highlight the conditioning role individual characteristics play in structuring the party-issue relationship, we focus on the moderating effect of a hitherto unexplored situational variable: the broader information environment. Since information processing and decision making is a function of individual predispositions and situational cues across a wide range of political domains (e.g., Krosnick and Kinder 1990; Marcus et al. 1995; Nelson, Clawson, and Oxley 1997; 
Sniderman, Hagendoorn, and Prior 2004; Stenner 2005), we believe the effect of situational factors, such as media coverage of elite political debate, should be examined when modeling the party-issue relationship across time.

We propose that individuals' party ties and issue attitudes dynamically constrain one another when the information environment is flush with germane political cues. In our framework, partisan loyalties and issue preferences serve as the most important individual factors while media coverage of elite political debate functions as the key situational cue. ${ }^{1}$ Such cues are present when political debate among partisan elites on some issue becomes subject to close scrutiny by the news media. When partisan leaders vigorously debate some matter, such as a proposed policy change, the appropriate response to a domestic or foreign policy crisis, a salient Supreme Court decision, or some other relevant controversy, news organizations take notice and provide ongoing coverage. They do so because such stories provide opportunities to emphasize conflict between competing sides. Frames like these are good for holding, if not enhancing, audience size and maintaining the appearance of ideological impartiality. Since balanced coverage of political debate among partisan elites allows the media to further these goals, they devote considerable attention to issue controversies (Graber 1997). The resultant coverage sends loud and clear signals to members of the mass public about the issues that divide the parties and where the parties stand on such matters.

On high-profile issues debated for extended periods of time, many people receive some exposure to these debates. However, even for those who do not customarily receive such signals, media coverage can indirectly promote updating. Individuals do not encounter each new political debate as blank slates. Instead, the existence of partisan stereotypes (Green, Palmquist, and Schickler 2002; Rahn 1993) and issue-handling reputations (Petrocik 1996) helps citizens navigate the complexities of the issue environment. To illustrate, the association between the GOP and the religious right, along with the perception that the party is hostile to the concerns of gays and lesbians, helps people see where the parties stand on gay rights. Likewise, the association of the Democratic Party with racial minorities allows people to infer where the parties stand on affirmative action (Brady and Sniderman 1985). Hence, even if someone does not pay much attention to news stories on high-profile issues, so long as she is aware of a debate's existence she can use party stereotypes to draw appropriate inferences and up-

${ }^{1}$ Zaller (1992) establishes that political awareness interacts with media coverage of elite debate to shape individual opinion change. We take up this possibility later in the article. date when necessary. Indirect awareness of issue debate can develop through episodic attention to the media, ${ }^{2}$ spill over coverage into soft media, discussion with friends or acquaintances, or some combination thereof. The net result is that many if not most people become aware of issue debate, even though they may be unfamiliar with the details.

Ultimately, political debate among partisan elites, through its generation of media coverage, should evoke partisan influence over issue preferences in the manner described by the classic (Campbell et al. 1960) or neoclassic (Green, Palmquist, and Schickler 2002) models of partisan perception, if not both. Put otherwise, the selective perception and belief endorsement mechanisms described above do not occur in an information vacuum. They become operative once they have been activated by the broader information environment.

In addition, our theory is sensitive to the possibility that issue preferences dynamically constrain partisan identities, at least when "easy" issues are being debated (Carmines and Stimson 1980). Most issues seem unlikely to shape partisanship in most situations; nevertheless, when elite conflict over long-standing, emotionally charged symbolic issues attracts pervasive media coverage, the prospect that issues shape party seems plausible. But if no such debate exists, or if news organizations are ignoring the matter, there will be no propensity for individuals to update their party tallies. Absent cues from the political context, we see little reason to expect citizens, who function as cognitive misers when processing political information, to initiate updating.

In sum, numerous studies have focused on the dynamic relationship between party identification and issue preferences. The typical approach is to use panel data to model individual-level partisan and issue attachments at time $t$ as a function of lagged values of each at time $t-1$ and ignore the potential impact situational cues may have on these links. We seek to extend the standard approach by analyzing whether individual-level relationships differ systematically as the information environment changes. Put otherwise, we seek to examine whether situational cues measured at the aggregate level influence relationships between preference variables measured at the individual level. In our theory, it is not elite debate that matters, nor elite division on the issue in question. Instead, what matters is that when partisan

\footnotetext{
${ }^{2}$ Indeed, Mondak (1993) and Berinsky (2007) have shown that the presence of a single elite party cue has the power to shift opinion on a given issue (e.g., "Ronald Reagan favors more defense spending"). In light of this, it seems fair to conclude that people need not encounter a steady stream of media-furnished cues to engage in updating.
} 
elites debate an issue and take stands consistent with their party labels, the media cover it, and citizens respond by updating.

We test two hypotheses to determine the extent to which the dynamics of political debate moderate the relationship between party identification and issue attitudes at the individual level. First, we predict that high levels of news media coverage of partisan elite debate on some issue lead individuals to update their policy attitudes and, to a lesser degree, their partisan identities to better reflect one another. Second, we predict that in the absence of media coverage of elite debate on a given issue, individuals eschew partisan and issue updating around said issue.

\section{Issue Selection and Justification}

Two conditions are necessary to test these hypotheses. First, we must identify significant issues that generated varying degrees of partisan elite debate and subsequent media coverage over time. Second, panel data that contain suitable preference questions for the relevant periods must be located. Based on these criteria, we identified four issues debated at various points during Bill Clinton's first term: health care reform, welfare reform, gay rights, and affirmative action. First, the Clinton health care plan drew vigorous opposition from conservative Republicans in 1994 (Jacobs and Shapiro 2000; Skocpol 1996). Second, Clinton's 1993 proposal to allow gays to serve openly in the military drew the ire of social conservatives and Republicans in Congress and caused some consternation in the mass public (Harris 2005). Media attention to gay rights continued thereafter due in part to debate over gay marriage. Third, affirmative action for African Americans became a notable controversy after the Supreme Court's 1995 ruling in Adarand v. Pena, which prompted Clinton to give a high-profile speech in which he argued, "[a]ffirmative action has been good for America” (quoted in Harris 2005, 189), and to propose amending rather than eliminating such programs. Republicans, including 1996 presidential nominee Bob Dole, expressed opposition to race-based affirmative action.

The final issue-welfare reform-presents an arguably less clear picture of partisan divisions, namely due to Clinton's 1992 campaign pledge to "end welfare as we know it." For two reasons, however, we expect updating around this issue to occur. First, although perhaps less clear than in the other three cases, the parties did disagree over the substance of welfare reform. Although Clinton signed welfare reform into law, he vetoed the first two
Republican-sponsored bills to leave Congress. Media accounts signaled that Republicans favored deeper cuts to welfare programs than Clinton and his Democratic allies in Congress. As a front-page New York Times article from April 28, 1996, noted, "The President ran on a promise 'to end welfare as we know it,' but he has vetoed Republican proposals to change the system, saying they are too draconian" (Wines 1996).

Second, we expect that partisan stereotypes led individuals to see the Democratic Party to the left of the GOP on welfare. Consistent with our party stereotype argument, Soss and Schram hold that " $[\mathrm{u}]$ nder AFDC, conflict over welfare largely followed party lines, which should have made it easier for publics to connect policy changes to broader political orientations" (2007, 114). Moreover, these scholars find that when welfare is made salient to the public, it advantages the Republican Party, regardless of the shifting stands of Democratic elites. In short, although the presence of mixed cues about welfare reform under Clinton may make updating harder on this issue, we still anticipate some degree of updating.

The other condition for testing our hypotheses requires the use of germane survey items appearing on a panel study that track the issues under debate. Fortuitously for us, the 1992-93-94-96 NES panel contains good measures for each of the aforementioned issues. We selected issues where identical questions were asked in three separate waves, thereby enabling us to apply structural equation modeling techniques to the opinion data in order to disentangle genuine attitude change from change due to the unreliability of the opinion items.

The issues we selected are well suited to testing our hypotheses. The varying levels of partisan elite debate over the years should lead to varying levels of media coverage and, ultimately, different degrees of individual-level updating. All four issues also represent long-standing points of disagreement between the parties. Indeed, arguments have been advanced that economic welfare issues, cultural issues, and racial issues represent the main fault lines in the American party system (Abramowitz 1994; Carmines and Stimson 1989; Layman 2001). Since these are easy issues for ordinary people to understand and partisan elites have taken clear positions on them for many years, they are precisely the types of issues that should prove susceptible to the influence of changing situational cues in the broader information environment. We make no claims, however, that symbolic issues like these can be treated as a representative sample of the issue universe. New issues or issues that cut across party lines likely make updating more difficult because voters cannot rely easily on enduring party stereotypes. 


\section{Measuring Individual Preferences}

We measure party identification using the standard 7point NES scale and the Democratic and Republican Party feeling thermometers. The 101-point feeling thermometers are combined into a single difference score measure (i.e., Republican score-Democratic score). Thus, the 7point scale and feeling thermometer difference variable serve as our observed indicators of latent party identification. ${ }^{3}$ The observed and latent partisanship variables are normed to a $0.00-1.00$ range whereby higher scores correspond to stronger Republican identifications.

We tap economic welfare attitudes as follows. First, for health care we rely on the standard question which asks respondents to place themselves on a 7-point scale indicating the direction and intensity of preferences for national health insurance versus private insurance. ${ }^{4} \mathrm{Next}$, for welfare preferences we employ a pair of items which ask whether federal spending on "welfare programs" and "food stamps" should be increased, decreased, or kept about the same. ${ }^{5}$ Since these are ordinal-level measures and the estimation method we use assumes interval-level data, responses from the 3-point items are added together to yield a 5-point scale. This scale more closely approximates, though far from perfectly, interval-level measurement than the single-item components, and hence, is better suited for use in structural equation models. ${ }^{6}$

Next, we measure attitudes toward social issues as follows. The gay rights indicator is composed of two items. The first question asks respondents whether they favor or

${ }^{3}$ See Goren (2005) for conceptual and empirical justification for this procedure. The statistical and substantive results reported below do not change when we rely solely on the 7-point scale to tap latent partisanship. Note that the alpha reliability coefficient for the party items averages .78 across the three waves.

4 "There is much concern about the rapid rise in medical and hospital costs. Some people feel there should be a government insurance plan which would cover all medical and hospital expenses for everyone. (Suppose these people are at one end of a scale, at point 1.) Others feel that all medical expenses should be paid by individuals and through private insurance plans like Blue Cross or some other company paid plans. (Suppose these people are at the other end, at point 7.) And, of course, some other people have opinions somewhere in between at points $2,3,4,5$, or 6 . Where would you place yourself on this scale, or haven't you thought much about this?" Respondents who failed to offer an opinion on the policy items are dropped from the analyses.

5 "Should federal spending on ... be increased, decreased, or kept about the same?" The alpha reliability coefficient for the welfare items averages .73 across the three waves.

${ }^{6}$ Note that when we estimate a structural model treating the welfare and food stamps items as separate measures of latent welfare preferences, the same pattern of results obtains. The same holds true for the gay rights models, as discussed below. oppose laws to protect homosexuals from job discrimination, the second whether or not they believe homosexuals should be allowed to serve in the U.S. armed forces. Both questions contain follow-up probes about whether respondents strongly or not strongly favor (oppose) such laws, which yield a pair of 4-point measures. ${ }^{7}$ We combine responses to both items to create a 7-point scale. Finally, attitudes toward affirmative action are tapped via a 4-point question on the degree to which respondents favor or oppose giving blacks preference in hiring and promotion because of past discrimination. ${ }^{8}$ As with partisanship, all observed and latent issue variables are set to a $0.00-1.00$ range, with higher scores denoting conservative preferences.

While the NES issue questions do not reflect all of the subtleties surrounding these policy debates, the items capture the basic idea underlying each issue reasonably well. First, the battle over health care reform in 1993 and 1994 focused heavily on Clinton's plan to achieve universal coverage via federal mandate, which overlaps significantly with the content of the health insurance question. Second, the welfare and food stamp spending questions are reasonable proxies for the broader issue of welfare redesign, although they do not map onto specific proposals that were on the table. Third, the gay rights indicators mirror the controversy over civil rights for homosexuals that raged during the 1990s. Whether or not homosexuals should be allowed to serve in the military was a very salient issue in 1993, while antidiscrimination laws against homosexuals received widespread national attention throughout Clinton's first term. Lastly, the affirmative action item focuses specifically on preferential hiring and promotion standards for African Americans. While affirmative action can apply to other domains, such as higher education, preferential hiring and promotion is a key component of the debate, and thus, the item we have serves as a solid proxy for affirmative action attitudes.

\footnotetext{
7"Do you favor or oppose laws to protect homosexuals against job discrimination?" Follow-up: "Do you favor (oppose) such laws strongly or not strongly?" Next, "Do you think homosexuals should be allowed to serve in the United States Armed Forces or don't you think so?" Follow-up: "Do you feel strongly or not strongly that homosexuals should (should not) be allowed to serve in the United States Armed Forces?" The alpha reliability coefficient for the gay rights items averages .65 across the three waves.

8 "Some people say that because of past discrimination, blacks should be given preference in hiring and promotion. Others say that such preference in hiring and promotion of blacks is wrong because it gives blacks advantages they haven't earned. What about your opinion-are you for or against preferential hiring and promotion of blacks?" The follow-up probe asks: "Do you favor (oppose) preference in hiring and promotion strongly or not strongly?"
} 


\section{Measuring Media Coverage of Elite Debate}

To test the proposition that news media coverage of issue debate among partisan elites is a necessary condition for people to update their political preferences, debate volume must be quantified accurately. We need to know how much media coverage there was for each issue during the NES panel waves to study the effect of the information environment on attitude change. To assess media coverage, we conducted a search of the Vanderbilt Television News Archives. The archives contain summaries of ABC, CBS, and NBC news content from 1968 to the present. For our analysis, we conducted an advanced search of the archives from January 1, 1992, through December 31, 1996, using a specified set of key words for our four issues. We restricted our sample of stories to the nightly news broadcasts and special programs, such as Nightline, on the three major broadcast networks. ${ }^{9}$

For each story that matched the search criteria, the abstract was read to ensure the story dealt explicitly with the issue in question. The vast majority of stories proved to be relevant; however, some matches were not included in the final story count for a given issue because they dealt with nonpolitical topics. For instance, a CBS evening news story on October 15, 1996, on the welfare of Irish ponies was dropped from the welfare story count. In addition, given our interest in race-based affirmative action, stories about gender-based affirmative action are excluded from that story count. Finally, we chose to exclude several stories about homosexuality we deemed nonpolitical, such as a CBS evening news feature on March 30, 1994, about an IKEA advertisement featuring a homosexual couple. ${ }^{10}$

The time frames used to count the stories is a function of when the questions appeared on the various waves of the survey. Some issue questions were included in the preelection surveys in 1992 and 1996, while others were included in the postelection surveys in 1992 and 1996. Therefore, the start and end dates for our story counts vary

${ }^{9} \mathrm{CNN}$ and Fox stories were excluded because news story summaries for these networks are not available in the archives for the entire time period under study.

${ }^{10}$ For health care reform we conducted a search using the phrase "health care reform." The welfare search was a Boolean search for "welfare" and "food stamp*." For gay rights we conducted a Boolean search for the words "gay*," "lesbian*," and "homosexual*." For affirmative action we conducted a Boolean search for "affirmative action" and "quota*." The asterisk captures any extensions of the stem words, although in the food stamp case it appears to have missed some mentions of the phrase "food stamps." For that reason a secondary search using the phrase "food stamps" was conducted. A full list of the coded stories is available from the authors upon request.

\section{TABLE 1 TV News Story Counts by Issue}

\begin{tabular}{lcc}
\hline Issue & Time $_{1}$ & Time $_{2}$ \\
\hline Health care reform & 561 & 10 \\
Welfare & 125 & 201 \\
Gay rights & 223 & 187 \\
Affirmative action & 4 & 108 \\
\hline
\end{tabular}

Notes: Time ${ }_{1}$ for health care reform and welfare/food stamps news stories is from Nov. 3, 1992, to Jan. 9, 1995, while Time 2 runs from. Jan. 10, 1995, to Nov. 4, 1996. Time 1 for gay rights runs from Jan. 13, 1993, through Nov. 24, 1993, while Time 2 runs from Nov. 25, 1993, through December 31, 1996. Time ${ }_{1}$ for affirmative action runs from Jan. 14, 1993, to Jan. 9, 1995, while Time 2 runs from Jan. 10, 1995, to Dec. 31, 1996.

Source: Compiled by the authors from the Vanderbilt Television News Archives.

across the issues. In 1993 and 1994, only one survey was conducted. To illustrate, the welfare story count runs from November 4, 1992 (the day after the final 1992 preelection survey) to January 9, 1995 (the last day of the 1994 survey) across the first time frame. For the second time frame, the story count runs from January 10, 1995 (the day after the 1994 survey) until November 4, 1996 (the last day of the 1996 preelection survey). Note finally that for the gay rights story count, the first time frame only includes 1993 stories since the gay rights questions were not asked on the 1994 survey, but were asked on the 1993 portion of the panel.

Table 1 summarizes the number of stories broadcast per issue during each panel wave. ${ }^{11}$ To begin, media coverage of elite debate on health care reform varied widely across the waves. Between the 1992 and 1994 surveys, 561 health care reform stories ran on $\mathrm{ABC}, \mathrm{NBC}$, and CBS combined. However, in the period between the 1994 and 1996 surveys, health care reform coverage virtually disappeared, with only 10 stories airing in a span of almost two years. The vast majority of stories about health care reform in the first period focused on the debate surrounding the Clinton reform proposal, such as stories on all three networks on September 30, 1993, about Hillary Clinton's congressional testimony on health care reform. Given this pattern of debate, we expect that individuals

\footnotetext{
${ }^{11}$ As a robustness check, we searched the ProQuest archive for New York Times front-page stories containing the key words, with minor modifications, from our Vanderbilt search. The general patterns from the New York Times data look very similar to the TV news story data, which gives us confidence that the TV news story counts serve as a valid measure of the information environment. The New York Times story counts and a description of our search procedures appear in the appendix.
} 
will update their party identifications and health care attitudes during 1992-94, but not during 1994-96. ${ }^{12}$

Turning to our second issue, welfare received considerable attention from 1992 through 1996. The second row of Table 1 shows that from the end of 1992 through early 1995 the networks ran 125 news stories on welfare and/or food stamps. From early 1995 through the end of 1996 the networks ran 201 stories. Many stories in both the first and second time frames focused on reform of the U.S. welfare system, such as a CBS segment on January 5,1994 , that chronicled where welfare reform stood on President Clinton's agenda for the year. In the second period, much of the coverage focused on the ongoing debate between Clinton and congressional Republicans about the substance of reform, including stories on $A B C$ and CBS on December 22, 1995, that highlighted the Republican Senate's passage of a welfare reform bill that Clinton vowed to veto. Since media coverage of elite debate over welfare was pronounced throughout the first Clinton term, we anticipate that individuals will update their party and welfare preferences in both the 1992-94 and the 1994-96 time periods.

The third row of Table 1 indicates the total number of gay rights stories in both time periods. As noted above, the gay rights issue was unique because there were no relevant questions on the 1994 wave of the NES panel; however, the questions we are interested in were asked in 1993. During the first period, which spans early 1993 to late 1993, the networks broadcast 223 political stories on gay rights. During the second period, which runs from late 1993 to late 1996, the networks ran 187 total stories. Many of the gay rights stories in time ${ }_{1}$ were related to the debate surrounding gays in the military, such as an ABC news story from May 11, 1993, about General Norman Schwarzkopf's opposition to President Clinton's plan to allow gays to serve openly in the military. During time 2 the gays in the military issue remained on the agenda, though to a lesser degree. However, the media continued to devote considerable attention to gay rights in response to partisan debate on the question of same-sex marriage. Since media coverage was fairly high throughout both periods, we expect citizens will have responded by updating their preferences on gay rights and partisan loyalties across both time frames.

\footnotetext{
${ }^{12}$ We are making an admittedly crude judgment that media coverage can be thought of in dichotomous terms: an issue either received widespread coverage in a given period or it did not. We acknowledge that this is an unsatisfying approach insofar as we do not identify the point at which an issue moves from one category to another. Empirically, it is not much of a problem in the current paper because the story count data in Table 1, as well as in the appendix, suggests natural cut-points.
}

Finally, media coverage of political debate on affirmative action differed markedly across the waves. Affirmative action stories were essentially absent between the 1992 and 1994 surveys, with only four stories in a roughly two-year span, but spiked between the 1994 and 1996 surveys, with 108 stories on the three networks. Part of the spike is attributable to salient Supreme Court rulings on affirmative action and Clinton's "mend it, don't end it" response, which garnered coverage on all three stations on July 19, 1995. Since media coverage was present only during the latter period, we predict that individuals will update their party identification and affirmative action preferences in the time 2 period, but not at time $e_{1}{ }^{13}$

\section{Statistical Analysis and Results}

We use structural equation modeling techniques to estimate the dynamic relationships between latent partisanship and latent issue attitudes. Our key concern is the impact individuals' party ties and policy preferences have on one another at time $t$, controlling for their lagged values at time $t-1$, in periods of varying media coverage of partisan elite debate. The structural equations of the models we estimate are as follows:

$$
\begin{aligned}
& \text { PARTY }_{\mathrm{t}}=\beta_{1} \text { PARTY }_{\mathrm{t}-1}+\beta_{2} \text { ISSUE }_{\mathrm{t}}+\zeta_{1} \\
& \text { ISSUE }_{\mathrm{t}}=\beta_{3} \text { ISSUE }_{\mathrm{t}-1}+\beta_{4} \text { PARTY }_{\mathrm{t}}+\zeta_{2}
\end{aligned}
$$

In these models, $\beta_{1}$ and $\beta_{3}$ represent the stability coefficients for latent partisanship and latent issue preferences, respectively. They function as relevant controls in the models and will not be discussed in our results. $\beta_{2}$ estimates the impact the latent issue preference has on latent party identification at time $t$, controlling for lagged partisanship, while $\beta_{4}$ estimates the impact partisanship has on issue preferences at time $t$, controlling for lagged issue preferences. ${ }^{14}$

\footnotetext{
${ }^{13}$ To check whether media stories signaled elite issue positions clearly, we selected a random sample of 20 abstracts for each issue and coded them for the presence of elite cues. For the health care, welfare, gay rights, and affirmative action issues, we found that $17,13,12$, and 14 stories, respectively, contained information on the issue positions of party elites. In most of these cases, the cues were consistent with party labels (i.e., Democrats favor health care reform, Republicans oppose it).

${ }^{14}$ Recall that we have two measures of partisanship and a single
measure of issue preferences at each of the three waves. The factor
loading is set to 1.00 for the 7 -point party scale at each panel
wave for latent party and to 1.00 for each issue item at each wave
for latent issue preferences. Moreover, we constrained the error
variances for the issue items to be equal across panel waves (see
Wiley and Wiley 1970). To avoid undue clutter and save space,
the factor loadings, variances, and covariances; error variances and
} 
We expect that $\beta_{2}$ and $\beta_{4}$ will be positive and statistically significant when partisan elite debate on the issue in question receives considerable media coverage. A positive and statistically significant $\beta_{2}$ coefficient will suggest that individuals update their partisan loyalties based on their current policy preferences (i.e., more conservative issue preferences enhance Republican ties). Similarly, a positive and statistically significant $\beta_{4}$ coefficient will indicate that partisanship shapes current issue preferences (i.e., stronger GOP ties lead to more conservative issue positions). Thus, we should see positive coefficients in the 1992-94 time frame for health care reform, in both periods for welfare and gay rights, and in 1994-96 for affirmative action, because media coverage was widespread on these matters (see Table 1). In contrast, we expect no relationships will be present for 1994-96 health care reform or for 1992-94 affirmative action, given the absence of high-profile debate. Finally, we anticipate that the differences in the coefficients will be statistically significant for the health care and affirmative action cases but not for welfare and gay rights. To sum up, we expect the causal relationship between party and issue will be demonstrably and significantly stronger in periods of high media coverage compared to periods of low/nonexistent media coverage.

Table 2 presents the estimates for the relationship between partisanship and health care attitudes. ${ }^{15}$ Our hypothesis is that positive and statistically significant coefficients will obtain in the first wave only and that these coefficients will differ significantly from their time ${ }_{2}$ counterparts. The estimates reveal that party identification and health care attitudes are positively related (holding lagged values constant) in 1992-94 but not in 1994-96. A formal test indicates that the effect of health care on partisan-

covariances; disturbances; and disturbance covariances are omitted from our tables. All of these estimates are available from the authors upon request.

${ }^{15}$ All models were estimated via robust maximum-likelihood (ML) estimation. Standard ML estimation assumes the variables are measured at the interval level and are multivariate normally distributed. When these assumptions are violated, $\chi^{2}$ tests and standard errors may be biased. Therefore, we use a robust (SatorraBentler) $\chi^{2}$ and robust standard errors, which generate more accurate results than the uncorrected ML statistics (Curran, West, and Finch 1996). Model fit is assessed via the $\chi^{2}$ test of global fit and three descriptive fit measures. The latter include the robust comparative fit index (CFI) where values of .95 or more reflect good fit; the standardized root mean squared residual (SRMR) with values of .08 or less denoting good fit; and the root mean square error of approximation (RMSEA) with values of .06 or less indicating good fit (Hu and Bentler 1999). Although the $\chi^{2}$ values are somewhat high (excepting affirmative action), the descriptive fit indices are generally excellent.

\section{TABLE 2 Party Identification-Health Care Model, Synchronous Structural Equation Estimates}

\begin{tabular}{|c|c|c|}
\hline & 92-94 & $94-96$ \\
\hline \multicolumn{3}{|l|}{ Stability coefficients } \\
\hline \multirow[t]{2}{*}{ Party identification } & $.93^{*}$ & $.96^{*}$ \\
\hline & .86 & .97 \\
\hline \multirow[t]{2}{*}{ Health care } & $.54^{*}$ & $.68^{*}$ \\
\hline & .52 & .76 \\
\hline \multicolumn{3}{|l|}{ Structural coefficients } \\
\hline \multirow[t]{2}{*}{ Health care $\rightarrow$ Party ID } & $.14^{*}$ & -.02 \\
\hline & .11 & -.01 \\
\hline \multirow[t]{2}{*}{ Party ID $\rightarrow$ Health care } & $.22^{*}$ & .05 \\
\hline & .27 & .07 \\
\hline \multicolumn{3}{|l|}{ Model fit } \\
\hline Robust $\chi^{2}$ & \multicolumn{2}{|c|}{$78.11^{*}$} \\
\hline Degrees of freedom & \multicolumn{2}{|c|}{21} \\
\hline Robust CFI & \multicolumn{2}{|c|}{.99} \\
\hline SRMR & \multicolumn{2}{|c|}{.04} \\
\hline RMSEA & \multicolumn{2}{|c|}{.08} \\
\hline
\end{tabular}

${ }^{+} \mathrm{p}<.10,{ }^{*} \mathrm{p}<.05$.

Notes: Robust maximum likelihood estimates based on raw data. Standardized estimates italicized. All factors on 0.00-1.00 scale. Factors coded so that higher scores denote stronger Republican partisanship and more conservative issue preferences; therefore, structural coefficients should be positively related. $\chi_{1}^{2}$ test for difference in health care effect on partisanship for $\mathrm{t}_{1}$ v. $\mathrm{t}_{2}=2.66, \mathrm{p}=$ $.103 ; \chi_{1}^{2}$ test for difference in partisanship effect on health care for $t_{1}$ v. $t_{2}=3.65, p=.056$; joint $\chi_{2}^{2}$ test for difference in both structural coefficients for $t_{1}$ v. $t_{2}=7.07, p=.029$. Factor loadings, variances, and covariances; error variances and covariances; disturbances; and disturbance covariances are omitted. $N=462$. Source: 1992-94-96 NES panel.

ship is probably larger in $\mathrm{t}_{1} \mathrm{v} \cdot \mathrm{t}_{2}\left(\chi_{1}^{2}=2.66, \mathrm{p}=.103\right)$. A comparable test reveals that the effect of partisanship on health care is larger in $t_{1} v . t_{2}\left(\chi_{1}^{2}=3.65, p=.056\right)$. More critically, a joint test that the respective effects are equal across the periods can be rejected $\left(\chi_{2}^{2}=7.07, \mathrm{p}=.029\right)$. These results, in conjunction with those of Table 1 which shows that elite debate on health care reform was covered extensively by the media from 1992 through 1994, imply that party ties and issue preferences induce changes in one another when the issue attracts media scrutiny.

How did citizens update? Table 2 indicates that the influence worked both ways. Increasing Republican partisanship led to more support for private market plans just as support for such plans reinforced Republican partisanship (both $\mathrm{p}<.05$ ). Although reciprocal causation is present, the influence of party identification on health care preferences exceeds that of health care on party. This 
TABLE 3 Party Identification-Welfare Model, Synchronous Structural Equation Estimates

\begin{tabular}{|c|c|c|}
\hline & 92-94 & 94-96 \\
\hline \multicolumn{3}{|l|}{ Stability coefficients } \\
\hline \multirow[t]{2}{*}{ Party identification } & $.94^{* *}$ & $.91^{* *}$ \\
\hline & .88 & .93 \\
\hline \multirow[t]{2}{*}{ Welfare } & $.71^{* *}$ & $.89^{* *}$ \\
\hline & .81 & .87 \\
\hline \multicolumn{3}{|l|}{ Structural coefficients } \\
\hline \multirow[t]{2}{*}{ Welfare $\rightarrow$ Party ID } & $.12^{* *}$ & $.07^{*}$ \\
\hline & .08 & .05 \\
\hline \multirow[t]{2}{*}{ Party ID $\rightarrow$ Welfare } & $.05^{+}$ & .04 \\
\hline & .07 & .06 \\
\hline \multicolumn{3}{|l|}{ Model fit } \\
\hline Robust $\chi^{2}$ & \multicolumn{2}{|c|}{$46.69^{*}$} \\
\hline Degrees of freedom & \multicolumn{2}{|c|}{21} \\
\hline Robust CFI & \multicolumn{2}{|c|}{.99} \\
\hline SRMR & \multicolumn{2}{|c|}{.03} \\
\hline RMSEA & \multicolumn{2}{|c|}{.05} \\
\hline
\end{tabular}

${ }^{+} \mathrm{p}<.11,{ }^{*} \mathrm{p}<.06,{ }^{* *} \mathrm{p}<.05$.

Notes: Robust maximum likelihood estimates based on raw data. Standardized estimates italicized. All factors on $0.00-1.00$ scale. Factors coded so that higher scores denote stronger Republican partisanship and more conservative issue preferences; therefore, structural coefficients should be positively related. $\chi_{1}^{2}$ test for difference in welfare effect on partisanship for $t_{1} v . t_{2} n s ; \chi_{1}^{2}$ test for difference in partisanship effect on welfare for $t_{1} v$. $t_{2} n s$. Factor loadings, variances, and covariances; error variances and covariances; disturbances; and disturbance covariances are omitted. $N=$ 546.

Source: 1992-94-96 NES panel.

holds for both the unstandardized $(.22>.14)^{16}$ and standardized $(.27>.12)$ estimates. Hence, while some party updating occurs, party identification acts as the stronger force in this relationship. More broadly, these estimates are consistent with our claim that media coverage of partisan elite debate must be present before citizens begin to reconsider their issue preferences and partisan loyalties. When media coverage of elite debate was high in 1992-94, citizens updated. Once the debate ran its course in 1995-96, issue and party updating ceased.

The estimates for the party identification-welfare preference model appear in Table 3. For this issue, we predict that updating occurs in both periods and that the coefficients will not differ across waves. This is precisely what we find. Our estimates suggest that welfare preferences shaped partisan ties, in the right direction, across

\footnotetext{
${ }^{16}$ Since the latent variables lie on a $0.00-1.00$ scale, the unstandardized coefficients can be directly compared to assess relative magnitudes.
}

both waves of the panel. Since welfare reform was debated at length during the first Clinton term (see Table 1), these results support our theoretical claims. However, there is less evidence that individuals' party loyalties systematically affected welfare preferences during this era. Lastly, the welfare-to-party and party-to-welfare effects do not differ significantly across panel waves. Since media coverage is roughly comparable across the waves, this finding is consistent with our expectations.

Current welfare preferences shape current partisan identities, controlling for lagged identities, at time ${ }_{1}$ and time $_{2}$. The impact of welfare preferences on party identification is statistically significant in the first period $(\mathrm{p}<.05)$ and nearly so in the second $(\mathrm{p}<.06)$. Thus, the stronger the antiwelfare sentiment, the more likely people were to move in a Republican direction. The substantive impact is not terribly large, whether gauged by the unstandardized (.12 in 1994 and .07 in 1996) or standardized (.08 in 1994 and .05 in 1996) coefficients. In light of this, care must be taken to avoid overstating the extent to which people updated party ties. Finally, there is some tentative evidence that party ties influenced welfare perceptions during the 1992-94 period $(\mathrm{b}=.05, \mathrm{p}<$ .11). This estimate suggests that Republican partisanship had a mild impact on welfare opposition. Overall, the key point is that the issue-party relationship endures as media coverage of partisan debate endures.

So far, we have seen that the political information environment moderates the relationship between party identification and issue preferences on matters of economic welfare. Does the same pattern of results hold when attention shifts to social issues like gay rights and affirmative action? Table 4 contains the estimates for the partygay rights models. We predict that updating should occur in both the first and second waves of the panel and that the structural coefficients will be statistically comparable in magnitude. As indicated in Table 1, the issue received extensive media coverage in time ${ }_{1}$ and time $e_{2}$. And, as indicated in Table 4, citizens responded by updating their party loyalties and issue preferences, presumably because the information environment furnished situational cues about "what goes with what." Moreover, consistent with expectations, the effect of gay rights on party and of party on gay rights does not differ significantly across panel waves.

According to the structural coefficients, attitudes toward gay rights influenced party identification in both periods $(\mathrm{p}<.05)$. Substantively, the more strongly one opposed gay rights, the more likely she was to move in the Republican direction. These effects, once again, are modest in magnitude, whether gauged in unstandardized (.09 in 1993 and .13 in 1996) or standardized (.09 in 1993 


\section{TABLE 4 Party Identification-Gay Rights Model, Synchronous Structural Equation Estimates}

\begin{tabular}{|c|c|c|}
\hline & 92-93 & $93-96$ \\
\hline \multicolumn{3}{|l|}{ Stability coefficients } \\
\hline \multirow[t]{2}{*}{ Party identification } & $.92^{*}$ & $.95^{*}$ \\
\hline & .90 & .90 \\
\hline \multirow[t]{2}{*}{ Gay rights } & $.86^{*}$ & $.97^{*}$ \\
\hline & .84 & .99 \\
\hline \multicolumn{3}{|l|}{ Structural coefficient } \\
\hline \multirow[t]{2}{*}{ Gay rights $\rightarrow$ Party ID } & $.09^{*}$ & $.13^{*}$ \\
\hline & .09 & .11 \\
\hline \multirow[t]{2}{*}{ Party ID $\rightarrow$ Gay rights } & $.09^{+}$ & -.05 \\
\hline & .10 & -.05 \\
\hline \multicolumn{3}{|l|}{ Model fit } \\
\hline Robust $\chi^{2}$ & \multicolumn{2}{|c|}{$51.42^{*}$} \\
\hline Degrees of freedom & \multicolumn{2}{|c|}{21} \\
\hline Robust CFI & \multicolumn{2}{|c|}{.99} \\
\hline SRMR & \multicolumn{2}{|c|}{.04} \\
\hline RMSEA & \multicolumn{2}{|c|}{.06} \\
\hline
\end{tabular}

${ }^{+} \mathrm{p}<.10,{ }^{*} \mathrm{p}<.05$.

Notes: Robust maximum likelihood estimates based on raw data. Standardized estimates italicized. All factors on $0.00-1.00$ scale. Factors coded so that higher scores denote stronger Republican partisanship and more conservative issue preferences; therefore, structural coefficients should be positively related. $\chi_{1}^{2}$ test for difference in gay rights effect on partisanship for $t_{1} v . t_{2} n s ; \chi_{1}^{2}$ test for difference in partisanship effect on gay rights for $t_{1} v$. $t_{2} n s$. Factor loadings, variances, and covariances; error variances and covariances; disturbances; and disturbance covariances are omitted. $N=$ 386.

Source: 1992-93-96 NES panel.

and .11 in 1996) terms. Party identification also appears to have shaped gay rights preferences during 1992-93 ( $\mathrm{p}<$ .10). The impact here was also quite modest (unstandardized effect $=.09$ and standardized effect $=.10$ ). However, party manifested no influence over gay rights preferences during 1993-96. More broadly, the Table 4 results confirm our key proposition. When the media cover political debate among partisan elites on an issue, citizens respond by bringing their policy preferences and partisan affinities more in line with one another.

The final relationship centers on citizens' partisan identities and their affirmative action attitudes. Recall from Table 1 that affirmative action was debated forcefully during the second half of Clinton's first term in office; therefore, we expect that the party and preference variables will be related at time 2 but not time $e_{1}$, and that the estimated coefficients will differ significantly across these periods. Table 5 confirms that this is the case. From 1992 to 1994 there was no debate to cover, so it comes as no sur-

\section{TABle 5 Party Identification-Affirmative Action Model, Synchronous Structural Equation Estimates}

\begin{tabular}{|c|c|c|}
\hline & 92-94 & 94-96 \\
\hline \multicolumn{3}{|l|}{ Stability coefficients } \\
\hline \multirow[t]{2}{*}{ Party identification } & $.96^{*}$ & $.92^{*}$ \\
\hline & .89 & .94 \\
\hline \multirow[t]{2}{*}{ Affirmative action } & $.66^{*}$ & $.92^{*}$ \\
\hline & .77 & .75 \\
\hline \multicolumn{3}{|l|}{ Structural coefficients } \\
\hline \multirow[t]{2}{*}{ Affirmative action $\rightarrow$ Party ID } & .06 & .01 \\
\hline & .05 & .01 \\
\hline \multirow[t]{2}{*}{ Party ID $\rightarrow$ Affirmative action } & -.01 & $.10^{*}$ \\
\hline & -.01 & .11 \\
\hline \multicolumn{3}{|l|}{ Model fit } \\
\hline Robust $\chi^{2}$ & \multicolumn{2}{|c|}{28.03} \\
\hline Degrees of freedom & \multicolumn{2}{|c|}{20} \\
\hline Robust CFI & \multicolumn{2}{|c|}{.99} \\
\hline SRMR & \multicolumn{2}{|c|}{.02} \\
\hline RMSEA & \multicolumn{2}{|c|}{.03} \\
\hline
\end{tabular}

${ }^{*} \mathrm{p}<.05$.

Notes: Maximum likelihood estimates based on raw data. Standardized estimates italicized. All factors on 0.00-1.00 scale. Factors coded so that higher scores denote stronger Republican partisanship and more conservative issue preferences; therefore, structural coefficients should be positively related. $\chi_{1}^{2}$ test for difference in partisanship effect on affirmative action for $t_{1} v \cdot t_{2}=2.57, p=.109$. Factor loadings, variances, and covariances; error variances and covariances; disturbances; and disturbance covariances are omitted. $N=476$.

Source: 1992-94-96 NES panel.

prise that individuals updated neither their party identifications nor their affirmative action preferences. However, after a plethora of stories on the affirmative action controversy appeared in 1995 and 1996, citizens used their party ties to update their affirmative action preferences. We can see that 1996 partisanship exerts a statistically significant and substantively modest effect (unstandardized effect $=.10$, standardized effect $=.11$ ) on 1996 affirmative action preferences. A formal test indicates that the effect of partisanship on affirmative action is likely larger in $t_{2}$ v. $t_{1}\left(\chi_{1}^{2}=2.57, p=.109\right)$. Substantively, this result implies that firmer attachments to the GOP were associated with increasing resistance to these programs. Lastly, there is no evidence that people used their affirmative action attitudes to modify their partisan leanings.

Overall, the results reported above lend some support to our theoretical expectations. We found that for all four issues the presence of high levels of media coverage prompted some form of individual-level updating. Sometimes party affected issues, sometimes issues 
affected party, and sometimes both processes occurred simultaneously. For the two cases where media coverage of debate was nonexistent, citizens did not update their issue preferences or party loyalties. In short, when political issues are debated by party leaders and covered by the television networks, citizens modify their issue preferences to reflect their partisan identities, and they reevaluate their partisan ties to reflect issue preferences.

\section{What about Individual Differences?}

To this point we have shown that situational factors (i.e., media coverage of partisan elite debate) interact with individual predispositions (i.e., partisan ties and issue preferences) to affect how those predispositions are updated over time. When media coverage of elite partisan debate is pronounced, citizens use their partisan identities to rethink their policy preferences and, to a lesser extent, use their issue preferences to rethink their partisan ties. Given our emphasis on media coverage of elite debate, a natural question to ask is whether these relationships are themselves conditional on political awareness or media exposure.

Two plausible alternatives are as follows. First, one might posit that partisan and issue updating are a function of how much people know about politics (i.e., political awareness) as well as the extent to which they are exposed to elite partisan debate in the news media (i.e., media exposure). Insofar as sophistication-based traits motivate people to follow political debate and help them see the implications elite cues have for their preferences, politically aware citizens should prove more adept at partisan and issue updating than the unaware (Converse 1964; Zaller 1992). Thus, the sophistication interaction perspective implies that the relationships observed in Tables 2-5 will be more pronounced among more informed subsets of the public.

In contrast, some recent research suggests that the ability to connect nonideological predispositions to policy preferences is not conditional on awareness. Put otherwise, although the ability to use liberal-conservative orientations to constrain issue preferences is dependent on prior knowledge, the same does not, generally speaking, hold true for alternative predispositions like core beliefs and, presumably, party ties (Goren 2004). The argument here is that most people can surmount the informationprocessing barriers of deducing preferences from simple political predispositions when the issue in question is symbolic, tied closely to party reputations, and highly salient. Since the issues analyzed here satisfy these condi- tions, the rival perspective holds that partisan and issue updating should occur at comparable rates for the aware and the unaware. In short, sophistication-related variables should not systematically affect the relationships observed above.

We tested these competing claims as follows. First, we crafted separate indicators of political awareness (using factual political knowledge scales) and media exposure (using campaign and media usage and exposure items). Second, we used median splits to divide samples into low versus high awareness groups as well as low versus high media exposure groups for each issue. Third, we reestimated each structural model, first for the low versus high knowledge groups, and then for the low versus high media usage groups. We found no evidence that the politically aware are more likely to update their party and issue leanings than the unaware as media coverage of elite partisan issue debate escalates. Likewise, we found no evidence that those more heavily exposed to news media are more prone to partisan or issue updating compared to those with less exposure. ${ }^{17}$ Put simply, we find no support for the sophistication interaction hypothesis.

These results suggest that individual differences in political awareness and media exposure do not matter, at least in the case of easy issues subject to intense media coverage. Although these results strike us as plausible under these conditions, we recognize that the case is far from settled. Given the limited number of cases we started with in the full samples (ranging from 386 to 546), the loss of additional cases to missing data on the sophistication moderators, and problems that can arise when structural equation models are estimated using small samples (Kline 1998), we felt compelled to use a median split on the awareness and exposure variables. However, a fairer test of the sophistication interaction hypothesis requires looking at groups of individuals who lie further up and down the awareness spectrum. We would have greater confidence in the conclusion that awareness does not matter if the same results held, say, for those in the bottom quintile of awareness or media exposure versus those in the top quintile. To reiterate, our data did not permit such a test. This is not to say that our tests are without value. Indeed, if significant differences emerged across median split samples, we would have uncovered strong evidence that awareness matters a great deal. But since we did not find such evidence, the proposition that individual differences do not matter must remain tentative pending the results of more powerful tests.

\footnotetext{
${ }^{17}$ These results are available from the authors upon request.
} 


\section{Conclusions and Implications}

In this article, we tested whether or not the political information environment moderates the relationship between citizens' party identifications and issue attitudes. We hypothesized that citizens will adjust their issue attitudes and party loyalties to conform to one another when news organizations cover divisions among partisan elites on an issue. ${ }^{18}$ Our statistical results offered reasonable support for our theory. Specifically, when the media focused on public discourse surrounding health care reform from 1992 through 1994, individuals updated their party ties and health care attitudes accordingly. When health care coverage disappeared from the airwaves in 1995-96, reevaluation ceased. Similarly, when news coverage of elite debate over affirmative action spiked in 1995-96, individuals modified their affirmative action attitudes. However, no updating occurred when affirmative action was off the agenda from 1992 through 1994. Finally, for gay rights and welfare reform, two issues where media coverage remained high from 1992 through 1996, individuals updated their party identifications and, to a somewhat lesser degree, their issue attitudes. To sum up, situational cues embedded within the information environment effectively conditioned the relationship between individual-level political identities and policy preferences.

There are important limitations to what the present study can say about the role the information environment plays in moderating party-issue ties. First, we analyzed only four issues during a four-year time span. Hence, caution must be exercised in generalizing from our estimates to other political eras or types of issues. It is well known that elite polarization increased dramatically during the 1990s (McCarty, Poole, and Rosenthal 2006). Polarized politics makes it easier for the public to notice partisan differences on the issues of the day relative to depolarized politics; therefore, we would not necessarily expect our results to hold in less polarized eras. However, since elite polarization seems likely to continue for some time, we expect future studies would yield similar results on relevant issues. Additionally, our theory and data do not provide clear insights into what updating might look like for new issues, hard issues, or issues which cut across traditional party lines. We suspect that in cases like these, updating would likely take different forms for different subsets of the electorate.

Second, the work of Carsey and Layman (2006) establishes that individual differences in issue salience and

\footnotetext{
${ }^{18}$ To reiterate, the key is that when partisan elites are divided on some issue and take stands consistent with their party labels, the media cover the conflict and citizens react to that coverage.
}

knowledge of where the parties stand on an issue moderate the relationship between partisanship and preferences. We examined whether political awareness and media exposure condition the dynamic relationship between party identification and issue preferences. Our results suggest that individual differences do not matter for the issues examined here. Unfortunately, data limitations forced us to conduct a rather crude test of the sophistication interaction hypothesis and we acknowledge this matter is far from closed. With better data, the proposition that individual-level variables like political sophistication and situational factors like media coverage jointly shape preference updating can be subjected to a more definitive test.

More broadly, our findings have a number of implications for public opinion scholarship and normative theories of democratic governance. First, these findings qualify the claim that party identification powerfully shapes political attitudes and beliefs by suggesting that its ability to do so depends on the broader information environment. With the notable exception of Zaller (1992), research on the party identification-issue attitude relationship has largely ignored the role political context plays in structuring these linkages. In contrast, we have demonstrated that party identification dynamically constrains issue attitudes when the media environment is awash with explicit cues about where the parties stand on the issue. Future work on partisanship should be attentive to the possibility that situational factors like the information environment condition the impact partisanship has on other political preferences.

In addition, our results furnish some evidence that issues can shape partisanship under certain conditions. On two issues, health care reform and affirmative action, we found that party identification shapes issue attitudes to a much greater extent than issues shape party. However, on two other prominent issues, welfare reform and gay rights, our estimates suggest that citizens' preferences shape, albeit modestly, their partisan leanings. Hence, our findings bolster Carsey and Layman's (2006) claim that issues affect party identification under some conditions.

Tying these strands together, our results dovetail nicely with the broader claim that political preference formation is a joint function of individual and situational factors. Prior work has shown that these two broad classes of factors interact to shape political judgment across a wide array of choices, such as citizens' judgments about civil liberties (Marcus et al. 1995; Nelson, Clawson, and Oxley 1997; Stenner 2005), presidential performance evaluations (Iyengar and Kinder 1987; Krosnick and Kinder 1990), and anti-immigration sentiments (Sniderman, Hagendoorn, and Prior 2004), to 
name a few. Our finding that varying levels of media coverage of elite debate regulate the party-issue relationship fits this perspective quite well.

Finally, these results suggest that ordinary citizens are more attuned to the contours of political debate on important issues than suggested by pessimistic accounts of citizen competence. While individuals do not appear to take the initiative to update their party identification or issue attitudes on their own, our findings imply that citizens respond in a meaningful fashion to changes in the information environment. When exposed to elite discourse about where the parties stand on salient social and political issues, individual citizens adjust their political priors accordingly. Importantly, however, our results suggest that individuals do not mindlessly adopt the positions taken by party leaders. Instead, on at least some issues, people are able and willing to modify their partisan attachments. In a representative democracy where the public is expected to hold elected officials and political parties accountable for their positions, it is reassuring that when elite debate around an issue spikes, many in the public are willing to reconsider their partisan loyalties in light of their policy preferences.

\section{Appendix: New York Times Front-Page Story Counts by Issue}

\begin{tabular}{lrrrrr}
\hline & \multicolumn{2}{c}{ Inclusive Count } & & \multicolumn{2}{c}{ Strict Count } \\
\cline { 2 - 3 } \cline { 5 - 6 } & Time $_{1}$ & Time $_{2}$ & & Time $_{1}$ & Time $_{2}$ \\
\hline Issue & & & & \\
Health care reform & 171 & 19 & & 156 & 19 \\
Welfare & 422 & 543 & & 303 & 473 \\
Gay rights & 202 & 285 & & 159 & 183 \\
Affirmative action & 38 & 116 & & 32 & 113 \\
\hline
\end{tabular}

Notes: Time $_{1}$ for health care reform and welfare/food stamps news stories are from Nov. 3, 1992, to Jan. 9, 1995, while $\mathrm{Time}_{2}$ runs from Jan. 10, 1995, to Nov. 4, 1996. Time 1 for gay rights runs from Jan. 13, 1993, through Nov. 24, 1993, while Time 2 runs from Nov. 25, 1993, through Dec. 31, 1996. Time 1 for affirmative action runs from Jan. 14, 1993, to Jan. 9, 1995, while Time 2 runs from Jan. 10, 1995, to Dec. 31, 1996.

Search Criteria. Using the ProQuest database, we searched the citation and document text of the New York Times, Late Edition (East Coast), for specific key words during our time frames. Only stories listed as appearing on p. A.1 or p. 1.1 where the headline, abstract, or full text contained the specified key word(s) are included. For health care reform, we searched for the phrase "health care reform." For affirmative action we searched stories for the words "affirmative action" or "quota" or "quotas." For welfare we searched for the words "welfare" or "food stamp*." Finally, we used the words "gay*," or "lesbian*," or "homosexual*," for the gay rights search. The asterisk picks up all extensions of the stem word. The only change from our Vanderbilt search was to use "quota" or "quotas" instead of searching quota*. We made this change because searching quota* produced numerous "quotation of the day" stories that made the search more time-consuming. We reviewed each story to ensure that the story dealt with the issue in question. When we were unsure about whether the story adequately captured attention to the issue in question, we marked the story and only included it in the inclusive count. Hence, the inclusive count above includes all stories using this more liberal coding standard whereas the strict count excludes these borderline cases. Finally, note that we did not include stories exclusively about foreign countries, or where the key word or phrase turned up in an unrelated context, such as discussion of trade "quotas."

\section{References}

Abramowitz, Alan I. 1994. "Issue Evolution Reconsidered: Racial Attitudes and Partisanship in the U.S. Electorate." American Journal of Political Science 38(1): 1-24.

Bartels, Larry M. 2002. "Beyond the Running Tally: Partisan Bias in Political Perceptions." Political Behavior 24(2): 117-50.

Baumgartner, Frank R., and Bryan D. Jones. 1993. Agendas and Instability in American Politics. Chicago: University of Chicago Press.

Berinsky, Adam J. 2007. "Assuming the Costs of War: Events, Elites, and American Public Support for Military Conflict.” Journal of Politics 69(4): 975-97.

Brady, Henry, and Paul M. Sniderman. 1985. "Attitude Attribution: A Group Basis for Political Reasoning." American Political Science Review 79(4): 1061-78.

Campbell, Angus, Philip E. Converse, Warren E. Miller, and Donald E. Stokes. 1960. The American Voter. New York: Wiley.

Carmines, Edward G., and James. A. Stimson. 1980. “The Two Faces of Issue Voting." American Political Science Review 74(1): 78-91.

Carmines, Edward G., and James A. Stimson. 1989. Issue Evolution: Race and the Transformation of American Politics. Princeton, NJ: Princeton University Press.

Carsey, Thomas M., and Geoffrey C. Layman. 2006. "Changing Sides or Changing Minds? Party Identification and Policy Preferences." American Journal of Political Science 50(2): 464-77.

Converse, Philip E. 1964. "The Nature of Belief Systems in Mass Publics." In Ideology and Discontent, ed. David Apter. New York: Free Press, 207-61. 
Curran, Patrick J., Stephen G. West, and John F. Finch. 1996. "The Robustness of Test Statistics to Nonnormality and Specification Error in Confirmatory Factor Analysis." Psychological Methods 1(1): 16-29.

Evans, Geoffrey, and Robert Andersen. 2006. "The Political Conditioning of Economic Perceptions.” Journal of Politics 68(1): 194-207.

Fiorina, Morris P. 1981. Retrospective Voting in American National Elections. New Haven, CT: Yale University Press.

Franklin, Charles H., and John E. Jackson. 1983. "The Dynamics of Party Identification.” American Political Science Review 77(4): 957-73.

Gaines, Brian J., James H. Kuklinski, Paul J. Quirk, Buddy Peyton, and Jay Verkuilen. 2007. "Same Facts, Different Interpretations: Partisan Motivation and Opinion on Iraq." Journal of Politics 69(4): 957-74.

Goren, Paul. 2002. "Character Weakness, Partisan Bias, and Presidential Evaluation." American Journal of Political Science 46(3): 627-41.

Goren, Paul. 2004. "Political Sophistication and Policy Reasoning: A Reconsideration." American Journal of Political Science 48(3): 462-78.

Goren, Paul. 2005. "Party Identification and Core Political Values.” American Journal of Political Science 49(4): 881-96.

Goren, Paul, Christopher M. Federico, and Miki Caul Kittilson. 2009. "Source Cues, Partisan Identities, and Political Value Expression." American Journal of Political Science 53(4): 805-20.

Graber, Doris A. 1997. Mass Media and American Politics. 5th ed. Washington, DC: CQ Press.

Green, Donald Philip, and Bradley Palmquist. 1990. "Of Artifacts and Partisan Instability." American Journal of Political Science 34(3): 872-902.

Green, Donald, Bradley Palmquist, and Eric Schickler. 2002. Partisan Hearts and Minds: Political Parties and the Social Identities of Voters. New Haven, CT: Yale University Press.

Harris, John F. 2005. The Survivor: Bill Clinton in the White House. New York: Random House.

Hu, Li-tze, and Peter M. Bentler. 1999. "Cutoff Criteria for Fit Indices in Covariance Structure Analysis: Conventional Criteria versus New Alternatives." Structural Equation Modeling 6(1): 1-55.

Iyengar, Shanto, and Donald R. Kinder. 1987. News That Matters. Chicago: University of Chicago Press.

Jacobs, Lawrence R., and Robert Y. Shapiro. 2000. Politicians Don't Pander: Political Manipulation and the Loss of Democratic Responsiveness. Chicago: University of Chicago Press.
Kline, Rex B. 1998. Principles and Practice of Structural Equation Modeling. New York: Guilford Press.

Krosnick, Jon A., and Donald R. Kinder. 1990. "Altering the Foundations of Support for the President Through Priming." American Political Science Review 84(2): 497-512.

Layman, Geoffrey. 2001. The Great Divide: Religious and Cultural Conflict in American Party Politics. New York: Columbia University Press.

Marcus, George E., John L. Sullivan, Elizabeth Theiss-Morse, and Sandra L. Wood. 1995. With Malice Toward Some: How People Make Civil Liberties Judgments. New York: Cambridge University Press.

McCarty, Nolan, Keith T. Poole, and Howard Rosenthal. 2006. Polarized America: The Dance of Ideology and Unequal Riches. Cambridge, MA: MIT Press.

Mondak, Jeffery J. 1993. "Source Cues and Policy Approval: The Cognitive Dynamics of Public Support for the Reagan Agenda." American Journal of Political Science 37(1): 186-212.

Nelson, Thomas E., Rosalee A. Clawson, and Zoe M. Oxley. 1997. "Media Framing of a Civil Liberties Conflict." American Political Science Review 91(3): 567-83.

Petrocik, John R. 1996. "Issue Ownership in Presidential Elections, with a 1980 Case Study." American Journal of Political Science 40(3): 825-50.

Rahn, Wendy M. 1993. “The Role of Partisan Stereotypes in Information Processing about Political Candidates." American Journal of Political Science 37(2): 472-96.

Skocpol, Theda. 1996. Boomerang: Clinton's Health Security Effort and the Turn against Government in U.S. Politics. New York: W. W. Norton.

Sniderman, Paul M., Louk Hagendoorn, and Markus Prior. 2004. "Predisposing Factors and Situational Triggers: Exclusionary Reactions to Immigrant Minorities." American Political Science Review 98(1): 35-49.

Soss, Joe, and Sanford F. Schram. 2007. "A Public Transformed? Welfare Reform as Policy Feedback." American Political Science Review 101(1): 111-27.

Stenner, Karen. 2005. The Authoritarian Dynamic. New York: Cambridge University Press.

Wiley, David E., and James A. Wiley. 1970. "The Estimation of Measurement Error in Panel Data.” American Sociological Review 35(1):112-17.

Wines, Michael. 1996. "G.O.P Is Preparing Budget Plan with Political Traps for Clinton.” New York Times, April 28.

Zaller, John R. 1992. The Nature and Origins of Mass Opinion. New York: Cambridge University Press. 